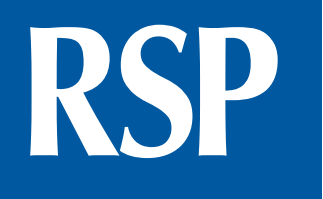

http://www.rsp.fsp.usp.br/

Revista de Saúde Pública

\title{
Interaction between demand-control and social support in the occurrence of common mental disorders
}

\author{
Amália Ivine Santana Mattos', Tânia Maria de Araújo", Maura Maria Guimarães de Almeida" \\ I Programa de Pós-Graduação em Saúde Coletiva. Universidade Estadual de Feira de Santana. \\ Feira de Santana, BA, Brasil \\ " Departamento de Saúde. Universidade Estadual de Feira de Santana. Feira de Santana, BA, Brasil
}

\section{ABSTRACT}

OBJECTIVE: To analyze the interaction between the psychosocial aspects of work and the occurrence of common mental disorders among health workers.

METHODS: This is a cross-sectional study conducted with a representative sample of workers of the primary health care of five municipalities of the State of Bahia, Brazil, in 2012. The variable of outcome were the common mental disorders evaluated by the SRQ-20, and the variables of exposure were high demand (high psychological demand and low control over the work) and low social support in the workplace. Interaction was checked by the deviation of the additivity of the effects for the factors studied from the calculation of excess risk from interaction, proportion of cases attributed to interaction, and the synergy index.

RESULTS: The global prevalence of common mental disorders was $21 \%$. The group of combined exposure has shown higher magnitude (high demand and low social support), reaching $28 \%$ when compared to the $17 \%$ in the situation of no exposure (low demand and high social support).

Correspondence:

Amália Ivine Santana Mattos Núcleo de Epidemiologia Universidade Estadual de

Feira de Santana

Av. Transnordestina, $\mathrm{s} / \mathrm{n}$

Novo Horizonte

44036-900 Feira de Santana,

BA, Brasil

E-mail: amalia0807@gmail.com

Received: 1 Jun 2015

Approved: 14 Jan 2016

How to cite: Mattos AIS, Araújo TM, Almeida MMG. Interaction between demand-control and social support in the occurrence of common mental disorders. Rev Saude Publica. 2017;51:48.

Copyright: This is an open-access article distributed under the terms of the Creative Commons Attribution License, which permits unrestricted use, distribution, and reproduction in any medium, provided that the original author and source are credited.
CONCLUSIONS: The results strengthen the hypothesis of interaction between the factors investigated, directing to the synergy of the effects.

DESCRIPTORS: Occupational Health. Mental Health. Working Conditions.Job Satisfaction. Burnout, Professional, epidemiology. Mental Disorders, epidemiology. Social Support. Job Strain Model. 


\section{INTRODUCTION}

The scientific literature points to the influence that work has on the lives of individuals ${ }^{18,19}$. Work can also contribute to change the physical and mental health of individuals, since it involves complex articulations of factors involving the body and the subjectivity of workers ${ }^{12}$. Work experiences that allow the individual to use fully their skills, express their creativity, and control significantly their work are reported as promoters of achievement, pleasure, health, and satisfaction ${ }^{15}$. On the other hand, the work developed under conditions that offer low control, with high psychological demands, marked by conflicting social relations, or characterized by social isolation (isostrain) may constitute an important factor for mental illness ${ }^{2}$.

Mental disorders related to work reach a significant portion of the Brazilian working population. They are responsible for the third place in the ranking related to the granting of sickness benefits ${ }^{25}$. Common mental disorders (CMD), of high occurrence among health workers, have been observed as a factor associated with presenteeism, absenteeism, and disabilities $^{22}$. Their occurrence among health workers is a problem of great relevance, because this implies impairment of the care provided to the user of the health system ${ }^{1}$.

Among the stressful events capable of causing CMD, we can mention the psychosocial aspects of work, which can be measured by the demand-control model, proposed by Karasek $^{17}$. The model allows for the prediction of four work experiences: low demand (high control/low demand), active work (high control/high demand), passive work (low control/low demand), and high demand (low control/high demand). Work experiences that combine high psychological demands and low control over the work offer increased job strain and, consequently, deleterious effects on the health of workers ${ }^{17}$.

Although suitable, the demand-control model was considered limited to grasp the complexity of the work process and its relationship with health outcomes. In this way, a third dimension was incorporated into the demand-control model: social support in the workplace. The inclusion of this third psychosocial aspect has been proposed by Johnson ${ }^{16}$, when considering that social support, a basic human need, would act as an important moderator of the impacts of high demands, what he has called as collective control. Social support refers to the proposal of a defensive ideology, since it consists in adopting collective strategies for the management of the hardships experienced in the work environment ${ }^{12}$.

Several authors have demonstrated that these three psychosocial dimensions of work - psychological demand, decision latitude, and social support - act as factors that interfere with the occurrence of outcomes related to health ${ }^{6}$. Thus, it is pertinent to consider the existence of an interaction between these dimensions, since this interaction is characterized by the deviation of the additivity of individual effects ${ }^{21}$. In the presence of two or more factors, the combined action differs from the simple act of each exposure separately, either for synergy or antagonism.

The study of the variability of diseases in human populations is one of the main objectives of epidemiology. However, the explanations for such variability are not easy to show, because explanatory models able to characterize how exposure contributes to the development of diseases are still hard to find in this field of knowledge. The evaluation of the interaction of factors for the occurrence of diseases is a privileged analysis alternative since, in a complex network of interaction of causes, interference in any of the factors that make it can deconstruct the entire framework responsible for generating the disease ${ }^{21}$.

There are few studies that have investigated the interaction between psychosocial aspects, considering the decision latitude, psychological demand, and social support in the workplace, and the occurrence of outcomes related to mental health ${ }^{8}$. We need to understand the complex mechanisms of interaction between these three psychosocial dimensions that trigger common mental disorders, since this knowledge can represent relevant gains toward the prevention of this issue among workers. The objective of this study has been to analyze 
the interaction between the psychosocial aspects of work (psychological demand, decision latitude, and social support) and the occurrence of CMD among health workers.

\section{METHODS}

This is a cross-sectional study conducted in five municipalities of the State of Bahia, Brazil, with health workers focusing on working conditions, employment, and health. We included service workers of the primary health care who were in full exercise of their activities. The representative sample was selected randomly, stratified by geographic area, level of complexity of the care, and occupational group. The data on the workforce of the units were supplied by the municipal departments of health of the municipalities studied. We selected the workers to participate in the study using lists of random numbers.

Data collection involved application of a research instrument constructed from the literature review. Interviewers were previously trained to standardize behaviors and a pilot study was carried out in a municipality of Bahia with 30 health workers. The data were collected in 2012 from visits to health units where the selected professionals worked. We used the strategy of replacing a professional of the same gender and professional category after three unsuccessful attempts to contact, as a procedure to reduce possible losses.

The variable of outcome was the CMD measured by the Self-Reporting Questionnaire (SRQ-20), an instrument composed of 20 dichotomous questions (yes, no) that evaluate the depressive, somatic, and anxiety symptoms that occurred in the last 30 days. In the evaluation carried out by Santos et al. ${ }^{23}$, the SRQ-20 obtained an acceptable performance to assess the mental health of workers in Bahia. The cutoff point for suspected CMD was seven or more positive responses. This cutoff point was considered as adequate in discriminating suspected cases in a study conducted with urban population ${ }^{24}$.

The variables of exposure were measured by the version translated to Portuguese of the Job Content Questionnaire (JCQ). The instrument is composed of 49 questions, distributed into five dimensions: physical demands, psychological demands, decision latitude, social support in the workplace, and job insecurity. In this study, the dimensions used were: psychological demands, decision latitude, and social support in the workplace. The questions of the JCQ are placed in a four-point ordinal Likert-type scale ("strongly disagree" to "strongly agree"). A study on the performance of the JCQ has shown that it is a good instrument to measure the psychosocial aspects of the work in Brazil ${ }^{5}$.

The score obtained for each dimension was categorized into high and low using the average as cutoff point ${ }^{4}$. After this procedure, we set the quadrants of the work situations provided for by the model: low demand, active work, passive work, and high demand. Low social support in the workplace and high demand were regarded as the most harmful categories of exposure to the health of workers.

The covariates considered in the analysis were: socio-demographic information (gender, age, number of children, marital status, education level, income), work characteristics (type of employment, weekly work, time working in the unit, labor rights, double employment, compatibility of the activities developed, job satisfaction, housework, excessive housework), and life habits (physical activities, leisure activities). Excessive housework was obtained by calculating: $\mathrm{SD}=$ (washing + ironing + cleaning + cooking) $\mathrm{x}$ (number of residents -1$)^{27}$. The score obtained was categorized in tertiles.

The analysis of the interaction involved the construction of dummy variables to establish the exposures: no exposure to any of the factors $=$ high social support, low demand $\left(\mathrm{R}_{00}\right)$, independent exposures $=$ high social support, high demand $\left(\mathrm{R}_{01}\right)$, low social support, low demand $\left(\mathrm{R}_{10}\right)$, and combined exposure $=$ low social support, high demand $\left(\mathrm{R}_{11}\right)$. The measures of interaction based on the additivity criterion were verified by calculating the excess risk due to interaction (excess risk due to interaction $-\mathrm{RERI}=\mathrm{PR}_{11}-\mathrm{PR}_{01}-\mathrm{PR}_{10}+1$ ), which quantifies the 
deviation from the null value, and the attributable proportion due to interaction (attributable proportion due to interaction $\left.-\mathrm{AP}=\left(\mathrm{PR}_{11}-\mathrm{PR}_{01}-\mathrm{PR}_{10}+1\right) / \mathrm{PR}_{11}\right)$, which shows the proportion of cases from both exposures and synergy index $\left(\mathrm{S}=\left(\mathrm{PR}_{11}-1\right) /\left(\mathrm{PR}_{01}+\mathrm{PR}_{10}-2\right)\right)$ that reflects the direction of the interaction in relation to nullity $(\mathrm{S}=1)$, synergy $(\mathrm{S}>1)$, or antagonism $(\mathrm{S}<1)^{21}$. We also calculated excess of prevalence (excess of prevalence $-\mathrm{EP}=\mathrm{P}_{\text {exposure }}-\mathrm{P}_{\text {no exposure }}$ ) and excess of prevalence ratio $(\mathrm{EPR}=\mathrm{PR}-1)$, which show whether the combined effect of the factors is greater than the sum of their individual effects, and relative difference $\left[\left(\mathrm{PR}-1 / \mathrm{EPR}_{01}+\mathrm{EPR}_{10}\right)-1\right]$, which shows the deviation of the expected behavior for the isolated action of the factors ${ }^{14}$.

The research project has been approved by the Research Ethics Committee of the Universidade Estadual de Feira de Santana (Protocol 081/2009). All phases of this study have met Resolution 466/12 of the Brazilian National Health Council, which addresses the guidelines and standards that regulate research with humans. All interviewees signed the informed consent.

\section{RESULTS}

The study population consisted of 2,532 young workers (average of 30.8 years), with female predominance (79.3\%), married and in a stable union (57.7\%), with high school (39.4\%), brown (56\%), and who practiced physical (70.4\%) and leisure (81.9\%) activities. Effective employment was referenced by $70.4 \%$ of the workers. Most claimed to have weekly workload of 40 hours (81.9\%), only one employment (78.7\%), time working in the unit of up to four years (51\%), only partial labor rights (62.3\%), and compatibility of the activities developed with the position (97.3\%). Job satisfaction was reported by $73.9 \%$ of the workers. The workers predominantly had high psychological demand (54\%), low decision latitude (59.4\%), and high social support (54.2\%). Work in high demand was experienced by $32.5 \%$ of the workers (data not shown in tables). Workers who experienced high demand presented greater percentages among those who had no partner (45.5\%), did no physical (51.7\%) or leisure (19.1\%) activities, were dissatisfied with their work (35.7\%), and had high excessive housework (32.9\%). The prevalence of CMD was higher in this group (26.2\%), suggesting that situations of greater vulnerability were concentrated in situations of high demand. Workers with low social support presented high percentages among males (20.4\%), who were 40 years old or more (41\%), with higher education (39.7\%), with income greater than two minimum wages (25.1\%), who did not practice physical (52.4\%) or leisure (19.9\%) activities, with no effective employment (30.8\%), working up to four years in the unit (49.4\%), dissatisfied with the work (34.6\%), and with higher prevalence of CMD (24.4\%) (Table 1).

The global prevalence of CMD in the population studied was $21 \%$. We observed the occurrence of CMD in $17 \%$ of those exposed to no factors and in $28 \%$ of those exposed to both factors. The combination of exposures presented a trend of increasing the crude prevalence ratios. The analysis of the effect of isolated factors showed that workers with high demand had higher prevalence of CMD than the reference group ( $\mathrm{PR}=1.41$; 95\%CI 1.02-1.94), as well as those who reported low social support in the workplace ( $\mathrm{PR}=1.05$; 95\%CI 0.67-1.62). Among those exposed to both high demand and low social support, we observed greater magnitude of association ( $\mathrm{PR}=1.64$; 95\% CI 1.21-2.22) (Table 2).

The difference between the expected prevalence for combined exposure $(\mathrm{P}=24.9 \%)$ and the prevalence observed for the group $(\mathrm{P}=28 \%$ ) exceeded the occurrence of the outcome in $3.1 \%$, according to the assumption of additivity. The association of the combined effect of high demand and low social support ( $\mathrm{PR}=1.64$ ) was higher than what was estimated based on the additivity of the effects $(\mathrm{PR}=1.46)$, resulting in $\mathrm{RERI}=0.18$. The attributable proportion due to interaction was $10.0 \%$ directed to the synergy of the effects $(S=1.39)$ (Table 2).

The data showed that $17 \%$ of the prevalence of the CMD corresponded to unknown exposures, which represent individuals who developed the disease even without being exposed to any of the factors investigated. On the other hand, $7 \%$ of the prevalence of the outcome was 
Table 1. Characteristics of workers according to the demand-control model and social support in the workplace. State of Bahia, Brazil, 2012.

\begin{tabular}{|c|c|c|c|c|c|c|c|c|c|c|c|c|}
\hline \multirow{3}{*}{ Variable } & \multicolumn{8}{|c|}{ Exposure: demand-control model } & \multicolumn{4}{|c|}{$\begin{array}{l}\text { Exposure: social support in the } \\
\text { workplace }\end{array}$} \\
\hline & \multicolumn{2}{|c|}{ Low demand } & \multicolumn{2}{|c|}{ Active work } & \multicolumn{2}{|c|}{ Passive work } & \multicolumn{2}{|c|}{ High demand } & \multicolumn{2}{|c|}{ High support } & \multicolumn{2}{|c|}{ Low support } \\
\hline & $n$ & $\%$ & $\mathbf{n}$ & $\%$ & $\mathbf{n}$ & $\%$ & $n$ & $\%$ & $\mathrm{n}$ & $\%$ & $n$ & $\%$ \\
\hline \multicolumn{13}{|l|}{ Gender } \\
\hline Female & 369 & 81.3 & 375 & 74.6 & 506 & 80.4 & 612 & 80.2 & 1,034 & 80.8 & 859 & 79.6 \\
\hline Male & 85 & 18.7 & 128 & 24.4 & 123 & 19.6 & 151 & 19.8 & 246 & 19.2 & 20 & 20.4 \\
\hline \multicolumn{13}{|l|}{ Age group (years) } \\
\hline Up to 40 & 257 & 57.9 & 290 & 58.8 & 351 & 56.8 & 441 & 58.6 & 374 & 59.3 & 627 & 59.0 \\
\hline More than 40 & 187 & 42.1 & 203 & 41.2 & 267 & 43.2 & 312 & 41.4 & 511 & 40.7 & 435 & 41.0 \\
\hline \multicolumn{13}{|l|}{ Marital Status } \\
\hline With partner & 256 & 56.4 & 305 & 60.9 & 371 & 59.0 & 419 & 55.0 & 723 & 56.7 & 633 & 58.6 \\
\hline Without partner & 198 & 43.6 & 196 & 39.1 & 258 & 41.0 & 343 & 45.0 & 553 & 43.3 & 447 & 41.4 \\
\hline \multicolumn{13}{|l|}{ Education level } \\
\hline Up to high school & 270 & 60.3 & 243 & 48.9 & 411 & 65.7 & 471 & 62.5 & 807 & 63.5 & 643 & 60.3 \\
\hline Higher education & 178 & 39.7 & 254 & 51.1 & 215 & 34.3 & 283 & 37.5 & 464 & 36.5 & 424 & 39.7 \\
\hline \multicolumn{13}{|l|}{ Income } \\
\hline Up to 2 minimum wages & 274 & 76.5 & 228 & 61.3 & 388 & 84.9 & 471 & 82.5 & 829 & 82.5 & 586 & 74.9 \\
\hline More than 2 minimum wages & 84 & 23.5 & 144 & 38.7 & 69 & 15.1 & 103 & 17.9 & 176 & 17.5 & 196 & 25.1 \\
\hline \multicolumn{13}{|l|}{ Physical activities } \\
\hline Yes & 235 & 52.5 & 286 & 57.9 & 329 & 52.8 & 366 & 48.3 & 695 & 55.0 & 509 & 47.6 \\
\hline No & 213 & 47.5 & 208 & 42.1 & 294 & 47.2 & 391 & 51.7 & 569 & 45.0 & 560 & 52.4 \\
\hline \multicolumn{13}{|l|}{ Leisure activities } \\
\hline Yes & 391 & 86.1 & 434 & 87.0 & 507 & 81.3 & 615 & 80.9 & 1,076 & 84.9 & 864 & 80.1 \\
\hline No & 63 & 13.9 & 65 & 13.0 & 117 & 18.8 & 145 & 19.1 & 191 & 15.1 & 214 & 19.9 \\
\hline \multicolumn{13}{|l|}{ Type of employment } \\
\hline Effective & 317 & 70.4 & 301 & 60.6 & 500 & 79.7 & 516 & 68.3 & 928 & 73.0 & 738 & 69.2 \\
\hline Not effective & 133 & 29.6 & 196 & 39.4 & 127 & 20.3 & 239 & 31.7 & 343 & 27.0 & 329 & 30.8 \\
\hline \multicolumn{13}{|l|}{ Time working in the unit (years) } \\
\hline Up to 4 & 227 & 51.6 & 213 & 44.3 & 325 & 54.2 & 350 & 47.4 & 584 & 48.4 & 511 & 49.4 \\
\hline More than 4 & 213 & 48.4 & 268 & 55.7 & 275 & 45.8 & 389 & 52.6 & 622 & 51.6 & 524 & 50.6 \\
\hline \multicolumn{13}{|l|}{ Satisfaction with the job } \\
\hline Satisfied & 384 & 84.6 & 399 & 79.3 & 451 & 71.8 & 489 & 64.3 & 1,033 & 80.8 & 706 & 65.4 \\
\hline Dissatisfied & 70 & 15.4 & 104 & 20.7 & 177 & 28.2 & 272 & 35.7 & 245 & 19.2 & 374 & 34.6 \\
\hline \multicolumn{13}{|l|}{ Excessive housework } \\
\hline Low & 207 & 47.2 & 260 & 53.6 & 252 & 40.9 & 327 & 44.2 & 531 & 42.9 & 481 & 46.2 \\
\hline Average & 98 & 22.3 & 96 & 19.8 & 164 & 26.6 & 169 & 22.9 & 290 & 23.5 & 247 & 23.8 \\
\hline High & 134 & 30.5 & 129 & 26.6 & 200 & 32.5 & 243 & 32.9 & 416 & 33.6 & 312 & 30.0 \\
\hline \multicolumn{13}{|l|}{ CMD } \\
\hline Yes & 75 & 16.6 & 87 & 17.9 & 127 & 20.8 & 197 & 26.2 & 232 & 18.6 & 257 & 24.4 \\
\hline No & 376 & 83.4 & 400 & 82.1 & 484 & 79.2 & 554 & 73.8 & 1,016 & 81.4 & 797 & 75.6 \\
\hline
\end{tabular}

CMD: Common mental disorders

Table 2. Prevalence and prevalence ratios of isolated and combined exposure according to the occurrence of CMD, in health workers. State of Bahia, Brazil, 2012.

\begin{tabular}{|c|c|c|c|c|}
\hline Variable & $\mathbf{n}$ & Prevalence of CMD (\%) & PR & $95 \% \mathrm{Cl}$ \\
\hline \multicolumn{5}{|l|}{ Reference } \\
\hline Social support $=0$, high demand $=0$ & 228 & 17.0 & 1.00 & \\
\hline \multicolumn{5}{|l|}{ Isolated exposures } \\
\hline Social support $=0$, high demand $=1$ & 325 & 24.0 & 1.41 & $1.02-1.94$ \\
\hline Social support $=1$, high demand $=0$ & 140 & 17.9 & 1.05 & $0.67-1.62$ \\
\hline \multicolumn{5}{|l|}{ Combined exposures } \\
\hline Social support $=1$, high demand $=1$ & 393 & 28.0 & 1.64 & $1.21-2.22$ \\
\hline Expected combined effect ${ }^{a}$ & & 24.9 & 1.46 & \\
\hline RERI $^{b}$ & & & 0.18 & \\
\hline $\mathrm{AP}^{\mathrm{c}}$ & & & 0.10 & \\
\hline$S^{d}$ & & & 1.39 & \\
\hline
\end{tabular}

CMD: Common mental disorders; PR: Prevalence ratio

a Expected combined effect $=\mathrm{P}_{01}-\mathrm{P}_{00}+\mathrm{P}_{10}-\mathrm{P}_{00}+\mathrm{P}_{00} / \mathrm{PR}_{01}-\mathrm{PR}_{00}+\mathrm{PR}_{10}-\mathrm{PR}_{00}+\mathrm{PR}_{00}$

${ }^{b}$ Excess risk due to interaction (RERI) $=\mathrm{PR}_{11}-\mathrm{PR}_{01}-\mathrm{PR}_{10}+1$

c Attributable proportion due to interaction $(\mathrm{AP})=\left(\mathrm{PR}_{11}-\mathrm{PR}_{01}-\mathrm{PR}_{10}+1\right) / \mathrm{PR}_{11}$

d Synergy index $(\mathrm{S})=\left(\mathrm{PR}_{11}-1\right) /\left(\mathrm{PR}_{01}+\mathrm{PR}_{10}-2\right)$ 
Table 3. Excess of prevalence and excess of prevalence ratios for isolated and combined effects of high demand and low social support in the workplace on the occurrence of CMD, in health workers. State of Bahia, Brazil, 2012.

\begin{tabular}{|c|c|c|c|c|c|}
\hline \multirow{2}{*}{ Variable } & \multirow{2}{*}{$\mathbf{n}$} & \multirow{2}{*}{ Excess of prevalence ${ }^{a}$} & \multicolumn{2}{|c|}{$\begin{array}{c}\text { Excess of prevalence ratio } \\
(E P R=P R-1)\end{array}$} & \multirow{2}{*}{$\begin{array}{c}\text { Relative difference } \\
\text { [(A/B) - 1] }(\%)\end{array}$} \\
\hline & & & Observed (EPRO) (A) & $\begin{array}{c}\text { Expected based on } \\
\text { separated exposure }^{\mathrm{b}} \text { (B) }\end{array}$ & \\
\hline \multicolumn{6}{|l|}{ Reference } \\
\hline Social support $=0$, high demand $=0$ & 228 & - & & - & \\
\hline \multicolumn{6}{|l|}{ Isolated exposures } \\
\hline Social support $=0$, high demand $=1$ & 325 & 7.0 & 0.41 & - & \\
\hline Social support $=1$, high demand $=0$ & 140 & 0.9 & 0.05 & - & \\
\hline \multicolumn{6}{|l|}{ Combined exposures } \\
\hline Social support $=1$, high demand $=1$ & 393 & 11.0 & 0.64 & 0.46 & 39 \\
\hline
\end{tabular}

CMD: Common Mental Disorders

${ }^{a}$ Excess of prevalence ratio $=\left(E P=P_{\text {exposure }}-P_{\text {no exposure }}\right)$

${ }^{\mathrm{b}}$ Excess of prevalence ratio expected based on separated exposure $=\mathrm{EPRO}_{01}+\mathrm{EPRO}_{10}$

recorded in the situation of high demand and $0.9 \%$ in low social support in the workplace. Exposure to both factors was responsible for $11 \%$ of the excess of prevalence. The combined effect of the factors ( $E P R=0.64)$ was greater than the sum of their isolated effects $(E P R=0.46)$. The relative difference between the estimates of the effects indicated a deviation of $39 \%$ of the expected behavior for the independent action of the factors (Table 3).

\section{DISCUSSION}

The demographic profile of the studied population showed similarity with other investigations carried out with primary health care workers: young individuals, mostly female, with only one job, and working for a short time in the unit ${ }^{13}$. The findings for the psychosocial characteristics of the work showed that most of the workers were exposed to high psychological demands and low decision latitude, similar to studies conducted among health professionals ${ }^{6}$. This shows a troubling reality, as this work experience increases the predisposition of workers to negative health outcomes ${ }^{4}$. On the other hand, most workers reported high social support in the workplace, a psychosocial aspect able to protect them from the negative influences of stress on their psychological and physical well-being, acting as a protective factor ${ }^{10}$.

The prevalence of CMD among workers was lower when compared to research studies conducted with health workers in Brazil ${ }^{3}$. However, it presented a relatively high prevalence (affecting one worker every five studied) and, therefore, cannot be neglected. Health work, as it obeys the logic of human labor, requires a mental conception that precedes the execution of the work in itself $^{18}$. In this sense, considering that the CMD will impose some level of impairment to the mental function of individuals, their occurrence is of great importance among health professionals. That is because their work is characterized by the peculiarity of their product, which is consumed the moment it is produced, reflecting the implementation of the activity in itself ${ }^{20}$. In addition, despite the findings on the quality of the care provided, they will significantly impact the well-being and quality of life of workers ${ }^{6}$.

The combined effect of high demand and low social support in the workplace showed higher occurrence of CMD than the expectation based on additivity, i.e., there are excessive events that characterize the synergism between the effects of these factors in the occurrence of the disease. The low decision latitude, the high psychological demand, and the low social support are an ideal scenario for adverse events among workers. On the other hand, high control, low demand, and high social support are the best work situation experienced and they contribute to promoting occupational health ${ }^{16,17}$.

The effects of the psychosocial aspects of the work on health have received considerable attention in recent years. The analysis of these aspects has been used successfully to predict 
the occurrence of mental disorders and other events related to health ${ }^{26}$. Evidence based on longitudinal studies shows that high levels of psychological demands and low control over work are predictive factors for mental disorders ${ }^{7}$. A study conducted with a population of workers in Sweden ${ }^{8}$ shows synergistic interaction between decision latitude and social support in the workplace for the occurrence of CMD.

The mechanisms that explain the association between stress at work and disease are based on the theory that chronic stress produces changes in the circadian rhythm of cortisol, which, in turn, implies in organic, emotional, and mental repercussions. In addition, stress at work can lead to the adoption of unhealthy behaviors by individuals, with equally negative consequences for the health. On the other hand, the buffer effect theory states that social connections bring health benefits by providing the resources needed to handle stress ${ }^{9}$. Thus, social support is a beneficial factor because it can reduce the perception of threats and it acts as an important environmental resource in the process of confronting adverse situations.

Social support is an essential psycho-social aspect in all sectors of work, but it is especially significant in the health work because of the relational character involved in the activities. It allows individuals to improve their ability to solve the problems presented by users and by the dynamics of the service, in their daily work, showing solidarity when faced with adverse situations, both witnessed and experienced. In addition, it enables the sharing of mutual commitments, in this case, the improvement of the health levels of the population cared for and the working conditions. It also contributes to job satisfaction and the feeling of recognition and appreciation for the effort undertaken with the health care provided ${ }^{a}$.

In primary health care, in addition to the aspects investigated, some factors can be mentioned as potentially causes of stress among workers, such as the growing number of temporary contracts, job insecurity, performance evaluation based on productivity, and lack of balance between private life and work. These factors are combined with the precarious conditions of life and health of the populations cared for, which increases the pressure on the workers and leads to greater occurrence of illness ${ }^{11,19}$. Therefore, in addition to the factors related to the psychosocial dimension of work, other factors must be evaluated among these workers.

This study has limitations. The interpretation of the associations between psychosocial aspects at work and CMD should be evaluated with caution. The information on both variables came from self-reports, which provides subjective data susceptible to bias. Because this is a cross-sectional study design, no causal relationships can be established. The simultaneous measurement of the exposures and the manifestation of the disease do not allow us to rule out alternative explanations for the associations found. In addition, there is a possibility of increased false-positive results, as workers with compromised health are more likely to report their work situation as being psychologically demanding, unlike healthy workers. Such a trend can lead to misclassification, which can result in both overestimation and underestimation of the true effect. There is still the possibility of healthy worker bias, as we have only included the participation of individuals who were in full exercise of their professional activities. Those who were eventually away, diseased by the work itself, were not part of the sample studied.

The results obtained strengthen the hypothesis of interaction between the psychosocial aspects of the work for the occurrence of CMD among health workers, directed to the synergy of the effects. Although similar investigations have not been identified for comparison, the literature points to plausibility for the associations found here. In this

a Ferreira RC. Apoio social no trabalho e absenteísmo-doença em trabalhadores de enfermagem [dissertation]. Rio de Janeiro (RJ): Escola de Enfermagem Anna Nery da Universidade Federal do Rio de Janeiro; 2010. way, it is pertinent to consider intervention in at least some of the factors investigated here, considering greater emphasis on aspects related to the organization of the work. This study may also contribute to the reflection on the psychosocial aspects and occupational health in the perspective of the relational nature of the work, in which social support plays a central role. 


\section{REFERENCES}

1. Alves AP, Pedrosa LAK, Coimbra MAR, Miranzi MAS, Hass VJ. Prevalência de transtornos mentais comuns entre profissionais de saúde. Rev Enferm UERJ. 2015;23(1):64-9. https://doi.org/10.12957/reuerj.2015.8150

2. Ansoleaga E. Indicadores de salud mental asociados a riesgo psicosocial laboral en un hospital público. Rev Med Chile. 2015;143(1):47-55. https://doi.org/ 10.4067/S0034-98872015000100006

3. Araújo TM, Aquino E, Menezes G, Santos CO, Aguiar L. Aspectos psicossociais do trabalho e distúrbios psíquicos entre trabalhadoras de enfermagem. Rev Saude Publica. 2003;37(4):424-33. https://doi.org/ 10.1590/S0034-89102003000400006

4. Araújo TM, Graça CC, Araújo E. Estresse ocupacional e saúde: contribuições do Modelo Demanda-Controle. Cienc Saude Coletiva. 2003;8(4):991-1003. https://doi.org/10.1590/S1413-81232003000400021

5. Araújo TM, Karasek R. Validity and reliability of the job content questionnaire in formal and informal jobs in Brazil. Scand J Work Environ Health. 2008;34 Suppl 6:52-9.

6. Braga LC, Carvalho LR, Binder MCP. Condições de trabalho e transtornos mentais comuns em trabalhadores da rede básica de saúde de Botucatu (SP). Cienc Saude Coletiva. 2010;15 Supl 1:1585-96. https://doi.org/ 10.1590/S1413-81232010000700070

7. Bültmann U, Kant IJ, Brandt PA, KasI SV. Psychosocial work characteristics as risk factors for the onset of fatigue and psychological distress: prospective results from the Maastricht Cohort Study. Psychol Med 2002;32(2):333-45. https://doi.org/10.1017/S0033291701005098

8. Choi B, Östergren PO, Canivet C, Moghadassi M, Lindeberg S, Karasek R, et al. Synergistic interaction effect between job control and social support at work on general psychological distress. Int Arch Occup Environ Health. 2011:84(1):77-89. https://doi.org/10.1007/s00420-010-0554-y

9. Cohen S, Wills TA. Stress, social support, and the buffering hypothesis. Psychol Bull. 1985;98(2):310-57. https://doi.org/10.1037/0033-2909.98.2.310

10. Cohen S. Social relationships and health. Am Psychol. 2004;59(8):676-84. https://doi.org/10.1037/0003-066X.59.8.676

11. Daubermann DC, Tonete VLP. Qualidade de vida no trabalho do enfermeiro da Atenção Básica à Saúde. Acta Paul Enferm. 2012;25(2):277-83. https://doi.org/10.1590/S0103-21002012000200019

12. Dejours C. A loucura do trabalho: estudo de psicopatologia do trabalho. São Paulo; Cortez; Oboré; 1992.

13. Dilelio AS, Facchini LA, Tomasi E, Silva SM, Thumé E, Piccini RX, et al. Prevalência de transtornos psiquiátricos menores em trabalhadores da atenção primária à saúde das regiões Sul e Nordeste do Brasil. Cad Saude Publica. 2012;28(3):503-14. https://doi.org/10.1590/S0102-311X2012000300011

14. Ferrite S, Santana V. Joint effects of smoking, noise exposure and age on hearing loss. Occup Med. 2005;55(1):48-53. https://doi.org/10.1093/occmed/kqi002

15. Glanzner $\mathrm{CH}$, Olschowsky A, Kantorski LP. Work as a source of pleasure: evaluating a Psychosocial Care Center team. Rev EsC Enferm USP. 2011;45(3):716-21. https://doi.org/10.1590/S0080-62342011000300024

16. Johnson J. Collective control: strategies for the survival in the workplace. In: Johnson JV, Johansson G. The psychosocial work environment: work organization, democratization and health. New York: Routledge; 1991. p.121-32. (Policy, Politics, Health and Medicines).

17. Karasek RA Jr. Job demand, job decision latitude, and mental strain: implications for job redesign. Adm Sci Q. 1979;24(2):285-308. https://doi.org/10.2307/2392498

18. Marx K. O capital: crítica da economia política: livro terceiro: o processo global de produção capitalista. Rio de Janeiro: Civilização Brasileira; 2013.

19. Oliveira MAC, Pereira IC. Atributos essenciais da Atenção Primária e a Estratégia Saúde da Família. Rev Bras Enferm. 2013:66 No Espe:158-64. https://doi.org/10.1590/S0034-71672013000700020

20. Pires D. Reestruturação produtiva e consequências para o trabalho em saúde. Rev Bras Enferm. 2000;53(2):251-63. https://doi.org/10.1590/S0034-71672000000200010

21. Rothman K, Greenland S, Lash T. Epidemiologia moderna. 3.ed. São Paulo: Artmed; 2011.

22. Sanderson K, Andrews G. Common mental disorders in the workforce: recent findings from descriptive and social epidemiology. Can J Psychiatry. 2006;51(2):63-75.

https://doi.org/10.1177/070674370605100202 
23. Santos KOB, Araújo TM, Oliveira NF. Estrutura fatorial e consistência interna do Self-Reporting Questionnaire (SRQ-20) em população urbana. Cad Saude Publica. 2009;25(1):214-22. https://doi.org/10.1590/S0102-311X2009000100023

24. Santos KOB, Araújo TM, Pinho PS, Silva ACC. Avaliação de um instrumento de mensuração de morbidade psíquica: estudo de validação do Self-Reporting Questionnaire (SRQ-20). Rev Baiana Saude Publica. 2010;34(3):544-60.

25. Silva Junior JS, Fischer FM. Adoecimento mental incapacitante: benefícios previdenciários no Brasil entre 2008-2011. Rev Saude Publica. 2014;48(1):186-90. https://doi.org/10.1590/S0034-8910.2014048004802

26. Solovieva S, Pensola T, Kausto J, Shiri R, Heliövaara M, Burdorf A, et al. Evaluation of the validity of job exposure matrix for psychosocial factors at work. PLoS One. 2014;9(9):e108987. https://doi.org/10.1371/journal.pone.0108987

27. Tierney D, Romito P, Messing K. She ate not the bread of idleness: exhaustion is related to domestic and salaried working conditions among 539 Québec hospital workers. Women Health. 1990;16(1):21-42.

Funding: National Council for Scientific and Technological Development (CNPq - Process 480611/2010-6), Fundação de Amparo à Pesquisa do Estado da Bahia (FAPESB - Process SUS0024/2009), and Coordination for the Improvement of Higher Education Personnel (CAPES).

Authors' Contribution: Design and planning of the study: AISM, TMA, MMGA. Collection, analysis, and interpretation of the data: AISM, TMA, MMGA. Preparation of the article: AISM, TMA, MMGA. Review of the article: AISM, TMA. Approval of the final version of the article: AISM, TMA, MMGA.

Conflict of Interest: The authors declare no conflict of interest. 